\title{
Importance of a Network of Online Labs in Magrebian Countries
}

\author{
http://dx.doi.org/10.3991/ijoe.v10i5.3795 \\ Ahmed Naddami ${ }^{1}$, Ahmed Fahli ${ }^{1}$, Mourad Gourmaj ${ }^{1}$, Andreas Pester ${ }^{2}$, Ramona Oros ${ }^{2}$ \\ ${ }^{1}$ Hassan $1{ }^{\text {st }}$ University, Khouribga, Morocco $-{ }^{2}$ Carinthia University of Applied Sciences, Villach, Austria
}

\begin{abstract}
Due to global economic factors, in Maghreb, there started short time ago and in the coming period will also continue a very high demand for technicians and engineers. In order to respond to this demand, the initial step is going to be to increase the capacity to train students in institutions of higher education in these countries. But at the same time an incompatibility between growth in numbers of students and quality of courses offered can appear. For this reason an innovative pedagogical approach, complementary to face-to-face pedagogy should be the solution. Integrating eLearning tools to develop a network of remote labs and online learning to build, sustain and share new training subjects in the purpose of providing high qualified students represents a success for the working market.
\end{abstract}

Index Terms-Online lab, remote control, network.

\section{INTRODUCTION}

A network of remote labs in North Africa that has the objective of modernization of higher education in science and technology should fit characteristics like:

- Adaptation of content to the development in science and technology, taking into account the expectations of the professional world

- Implementation of practical courses for on-distance education

- Creating teaching units in the eLearning format

- Setting up and using an LMS (Learning Management System)

- Evaluation of the newly created educational resources

- Use of the pedagogical resources

\section{State of the ART In Maghrebian Countries}

The most important requirement of engineers in African countries is in Morocco, Tunisia and Algeria.

The need for qualified human resources such as technician and engineer is now a major concern given the economic and industrial development of Morocco in the field of technology. From national study done recently a need for engineers and technicians up to 9000 people till 2015 in fields like Aerospace and Electronics was a highlight. To train these engineers and technicians, it lacks specialized rooms for practical work [8]. For this reason a network of practical work possibilities represents the most reliable solution.

The situation in Tunisia is close connected to the economic globalization that has created new challenges in Tunisia that forced higher education institutions to evolve. In engineering education the results are encouraging: Tunisia had 37 engineering graduates per 100,000 inhabitants (86 in France and 165 in Korea as shown by OECD statistics in 2006). These numbers have risen to 44 per 100,000 engineering in Tunisia in 2008. The aim is to increase the number of engineers per year from 3500 to
7000 by 2015 to achieve the ratio of developed countries. Encouraging the use of distance education, the government made available to institutions of higher education facilities equipped for distance education.

And Algerian higher education has undergone major changes related to changing in the socio-economic environment since 2004. Many measures have been taken to develop emerging technologies, resulting in a growth of $6 \%$ to $10 \%$ for the electronics industry, $68 \%$ for mobile telephony. Sixteen large companies are very active in this area. Sétif region-Bordj Bou Arreridj are among the most dynamic Maghreb, in the electronics industry. Several global electronics giants (including SAMSUNG, CONDOR...) are located there. Human resources related to these technologies should evolve and considerable effort is implemented in the training of engineers and technicians to make them more efficient and competitive.

However, one of the recurring problems for all magrebian countries is the lack of practical training rooms and equipment.

\section{AVAILABLE REMOte LABS}

To strengthen the training of engineers and technicians with innovative pedagogy, the Ministry of Higher Education from different countries has made available to academic institutions, facilities and support for distance education.

In this framework first remote lab that was implemented in Maghreb was developed by a team of researchers of Khouribga OnlineLab, Polydisciplinary Faculty in Khouribga (PFK) -Hassan $1^{\text {st }}$ University in Morocco. In this work the main objective is to build an interactive an and flexible remote laboratory system to determine the synchronous reactance at any time with any browser in real-time using a client interface (Figure 2) which is implemented using National Instrument LabVIEW and deployed as an interactive lab in the ISA.

The ISA provides a common framework on which laboratory instrumentation can be integrated to create remote laboratories [3] that allow students to conduct and run laboratory equipment's remotely through internet, also designed to use online labs to scale a large number of users geographically dispersed through the world [4].

There are three different types of architecture available in the lab framework of online laboratories: Batched experiment, Sensor experiment and Interactive experiment [5].

For this student must download and install the LabVIEW plug-in for their browser available at: http://www.ni.com/.

Hardware part of the platform is controlled by using National Instruments' CompactRIO based on reconfigura- 
ble Filed-Programmable Gate Array (FPGA) technology and real-time processor [9].

The Synchronous reactance experiment installation has a real-time webcam streaming, students see the live scenes of experiment and believing are working and controlling real motor running, they can learn the real values of current and voltage being measured through digital displays installed in the test bed based on synchronous machine. (Figure 2 and Figure 3).

Synchronous machines are AC machines that have a field circuit supplied by an external DC source it is reversible: it can operate as a motor or generator (alternator) but the most common application of the synchronous machine is in the power industry as a three phase generator [4]-[7].

In a synchronous generator, a DC current is applied to the rotor winding producing a rotor magnetic field. The rotor is then turned by external means producing a rotating magnetic field, which induces a 3-phase voltage within the stator winding [4].

In a synchronous motor, a 3-phase set of stator currents produces a rotating magnetic field causing the rotor magnetic field to align with it. The rotor magnetic field is produced by a DC current applied to the rotor winding.

\section{CONCLUSIONS}

A network of remote labs will help magrebian students to access more experiments in inter - disciplinary field. Like this high qualified engineers can share their experiences and to be good prepared for the needs of the working market.

\section{ACKNOWLEDGMENT}

This project has been funded with support from the European Commission. This publication reflects the views only of the author, and the Commission cannot be held responsible for any use which may be made of the information contained therein

\section{REFERENCES}

[1] K. D. Kim Kimberly, V. JudsonHarward, Philip Bailey, James Hardison, Gordon Kohse, Yakov Ostrocsky"Three Online Neutron Beam Experiments Based on the iLabShared Architecture", (EDUCON), Madrid pp.145 -150, 14-16 April 2010.

[2] Jiwaji, A., J. Hardison, K. P. Ayodele, S. Stevens, A, Mwanbela, V. J. Harward, J. A. del Alamo, B. Harrison, and S. Gikandi, "Collaborative Development of Remote Electronics Laboratories: The ELVIS iLab." 2009 ASEE Annual Conference \& Exposition. Austin, TX, June 14-17, 2009.

[3] V.J Harward, et al, "The iLab Shared Architecture: A Web Services Infrastructure to Build Communities of Internet Accessible Laboratories," Proceedings of the IEEE , vol.96, no.6, pp.931-950, June $2008 \mathrm{http}: / / \mathrm{dx}$.doi.org/10.1109/JPROC.2008.921607

[4] F.H.;Ali, H.M, Mahmood, S.M.B Ismael, "LabVIEW FPGA implementation of a PID controller for D.C. motor speed control "International Conference on Energy, Power and Control (EPCIQ), Basrah pp.139-144, Nov. 30 2010-Dec. 22010.

[5] B. P. Karen, H. M. Chou (2011). Real-Time Rapid Embedded Power System Control Prototyping Simulation Test-Bed Using LabVIEW and RTDS, Practical Applications and Solutions Using LabVIEW ${ }^{\text {TM }}$ Software, Dr. Silviu Folea (Ed.), ISBN: 978-953307-650-8, InTech.

[6] G. Z. Danilo, P. Andreas, A. Michael, M. Christian, " Remote Applications and Trends", E-pragmatic module, 2011,

[7] G. Z. Danilo, A. Michael, "Work in Progress Integrating Educational Online Lab Platforms around the iLab Shared Architecture", 41st ASEE/IEEE Frontiers in Education Conference, Rapid City, 2011

[8] T. Zimmer, D. Geoffroy, A. Pester, R. Oros, T. Tsiatsos and S. Douka, "eScience: Setting up a network of remote labs in the magrebian countries" Proceeding ICEER 2013, 1 - 5 July, Marrakesh Morocco

[9] http://www.ni.com/

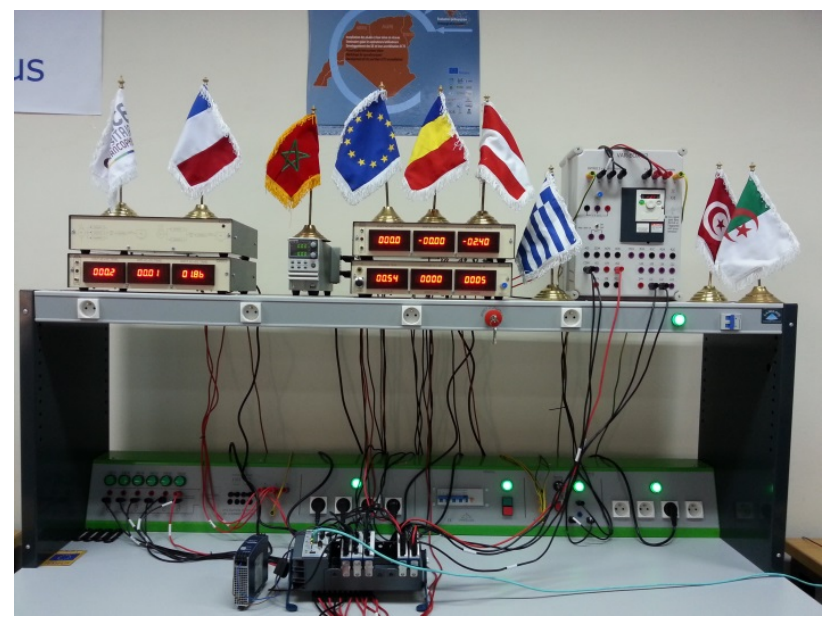

Figure 1. Hardware stand equipment

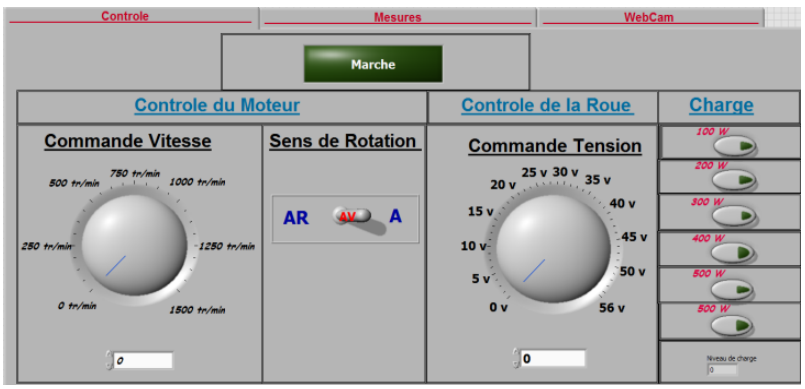

Figure 2. LabVIEW client interface

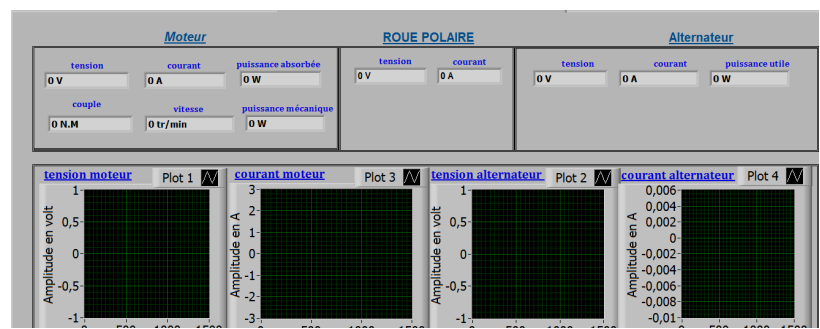

Figure 3. LabVIEW client interface - Determination of the reactance

\section{AUTHORS}

Ahmed Naddami is with the Department of Electrical Engineering, The Polydisciplinary Faculty in Khouribga, Hassan $1^{\text {st }}$ University-Settat, Morocco (e-mail: ahmed.naddami@gmail.com).

Ahmed Fahli is with the Department of Electrical Engineering, The Polydisciplinary Faculty in Khouribga, Hassan $1^{\text {st }}$ University-Settat, Morocco (e-mail: fahli@uhp.ac.ma).

Mourad Gourmaj is with the Department of Electrical Engineering, The Polydisciplinary Faculty in Khouribga, Hassan $1^{\text {st }}$ University-Settat, Morocco (e-mail: mourad.gourmaj@gmail.com).

Andreas Pester is with the System Engineering and IT - Carinthia University of Applied Sciences, Villach, Austria (e-mail: A.Pester@fh-kaernten.at).

Ramona Oros is with the System Engineering and IT Carinthia University of Applied Sciences, Villach, Austria (e-mail: R.Oros@fh-kaernten.at). 